\title{
La protección del ambiente glacial
}

\section{Glacial environment protection}

\author{
Liber Martin* y Mauricio Pinto"
}

Se presenta una revisión sintética del desarrollo de la regulación argentina en materia de preservación de glaciares y medio ambiente periglacial, incluyendo i) el marco jurídico general de protección de las aguas en Argentina; ii) los antecedentes de la Ley N²6.639 de 2010 sobre protección de glaciares y medio ambiente periglacial; iii) la conflictividad generada entre la protección glacial y la minería, y vi) las principales cuestiones controvertidas de la aplicación de la Ley $\mathrm{N}^{\circ}$ 26.639 de 2010.

Palabras clave: Glaciares, ambiente periglacial, protección ambiental, aguas, Derecho de aguas, Derecho de Recursos Naturales.
A synthetic review of the development of Argentina's regulation concerning the preservation of glaciers and periglacial environment is presented, including: i) the general legal framework for water protection in Argentina; ii) the history of Law $\mathrm{N}^{\circ}$ 26.639 of 2010 , on the protection of glaciers and periglacial environment; iii) the conflict generated between glacial protection and mining protection; and iv) the main controversial issues of the implementation of Law $N^{\circ} 26,639$ of 2010.

Key words: Glacials, periglacial environment, environmental protection, water resources, Water Law, Natural Resources Law.

\section{Introducción}

En las últimas décadas los glaciares han comenzado a ser percibidos como elementos de suma fragilidad. El hecho de que los devastadores efectos del cambio climático hayan comenzado a manifestarse sobre estas formaciones, sumado a la toma de conciencia de que más de las dos terceras partes del agua dulce existente en el mundo se encuentra en estado sólido conformando cuerpos glaciales, ha generado movimientos sociales que propician su especial protección.

\footnotetext{
* Profesor de la Universidad Nacional de Cuyo, e investigador en CONICET. Doctor en Derecho Universidad de Zaragoza (2009). Correo electrónico: libermartin@gmail.com.

** Profesor e investigador de la Facultad de Ciencias Económicas y Jurídicas de la Universidad de Aconcagua, y profesor en la Universidad Nacional de Cuyo Universidad de Mendoza. Correo electrónico: mpinto@irrigacion.gov.ar
}

Recibido el 18 de abril y aceptado el 9 de junio de 2014. 
En el ámbito jurídico, tales movimientos han impactado en el surgimiento de normas y procesos legales que ponen por centro de acción la tutela de tales formaciones geográficas, limitando las actividades humanas perjudiciales.

En Latinoamérica, la naturaleza de Argentina y Chile presenta un lugar preponderante en la temática; de los $25.500 \mathrm{~km}^{2}$ de glaciares que existen en Sudamérica, la cadena andina que comparten ambos países alberga cerca del $90 \%$ de los mismos, principalmente en su vertiente occidental.

Normativamente, Argentina ha avanzado de manera notoria en la regulación de las actividades que pueden afectar a dichos accidentes geográficos, dictando a través de la Ley N²6.639, de 2010, de Presupuestos Mínimos para la Preservación de los Glaciares y del Ambiente Periglacial (en adelante Ley $\mathrm{N}^{\circ}$ 26.639), un régimen básico de aplicación en todo el territorio nacional. Chile, en cambio, aún no ha logrado tal estándar regulatorio, y aunque el inicial proyecto legislativo en la materia propuesto en 2006 se archivó en 2007, desde el 2013 las autoridades legislativas han revitalizado el análisis de tal temática, siendo indudablemente un tema en la actual agenda legislativa ${ }^{1}$.

El presente trabajo pretende revisar diversos aspectos que hacen a la experiencia normativa que Argentina presenta en esta materia, incluyendo la integración del régimen sobre tutela de los cuerpos glaciares al régimen jurídico de las aguas, su vinculación con los conflictos mineros ambientales y los aspectos conflictivos que presenta el contenido de la Ley $N^{\circ}$ 26.639, de 2010.

Aunque no aspiramos a concretar un análisis abarcativo de todos los aspectos que pueden ser incluidos en la temática, sí pretendemos delinear los principales elementos de la regulación como experiencia normativa, en la inteligencia de que en dicha reseña pueden encontrarse elementos de valor no solo para replantear algunos de sus aspectos, sino también para extrapolar tales consideraciones a otras regulaciones que se encuentran en formación.

\section{Marco jurídico de la protección de las aguas en el Derecho argentino}

1. Marco constitucional y leyes de presupuestos mínimos de protección ambiental

La Constitución de la Nación Argentina, de 1994 (en adelante, CN) establece un régimen federal de Gobierno en el marco del cual coexisten un Estado nacional con 23 Estados provinciales y una Ciudad autóno-

\footnotetext{
1 Noticias del Senado, 2014.
} 
ma, disponiendo un complejo sistema de distribución de competencias entre los estamentos nacional y provinciales donde existen competencias delegadas a favor del Estado nacional, reservadas en los Estados locales, concurrentes entre ambos ámbitos, y de regulación básica nacional y complementación local. En ese esquema, fuera de las potestades expresamente otorgadas a la Nación, los Estados provinciales conservan todos los poderes no delegados (art. $121 \mathrm{CN}$ ).

Acorde a ello, si bien la potestad de regular sobre la generalidad de los recursos naturales no ha sido delegada nacionalmente $-y$ con ello se encuentra reservada en las autoridades provinciales-, facultad de dictar el Código de Minería ha sido delegada al poder legisferante federal (art. 75 inc. $12 \mathrm{CN}$ ), pero sin que tal potestad altere la jurisdicción local, correspondiendo por ello su aplicación -y consiguiente desarrollo procedimental- a la autoridad local. Por su parte, se ha reconocido a las provincias el dominio originario de los recursos naturales (art. $124 \mathrm{CN}$ ), y en consecuencia la competencia para disponer de ellos y establecer los derechos relativos a sus usos.

En materia ambiental, la reforma constitucional de 1994 estableció que "Corresponde a la Nación dictar las normas que contengan los presupuestos mínimos de protección, y a las provincias, las necesarias para complementarlas, sin que aquellas alteren las jurisdicciones locales" (art. $41 \mathrm{CN}$ ). Sobre la base de esos presupuestos mínimos fijados por la Nación, cada provincia dicta su propio régimen complementario, pudiendo incrementar, mas no disminuir los niveles de protección ambiental establecidos por aquellos presupuestos básicos, debiendo las autoridades provinciales ejercer la jurisdicción que implica la aplicación normativa.

En función de esta nueva competencia ambiental, la Nación comenzó a dictar una profusa legislación sobre presupuestos mínimos, entre las que destacan para la conformación del régimen de protección ambiental de las aguas tanto la Ley N²5.675, de 2002 (sobre Política Ambiental Nacional), como la Ley $N^{\circ}$ 25.688, de 2003 (sobre gestión de aguas), y la Ley $\mathrm{N}^{\circ} 26.639$, de 2010.

\section{Legislación provincial}

En función de las competencias reservadas, la mayoría de las provincias argentinas cuenta desde hace tiempo con específicas leyes de aguas que, además de regir el uso y aprovechamiento del recurso hídrico, generalmente también regulan aspectos vinculados a la protección ambiental del recurso. Además, desde la década del noventa con leyes ambientales locales específicas que contemplan la protección del recurso hídrico. 
Pero además, en consonancia con el crecimiento de la actividad minera y acorde a los conflictos sociales que ello ha generado ${ }^{2}$, dentro de las normativas ambientales-mineras ${ }^{3}$ ha resultado especialmente polémica la restricción y/o prohibición específica que muchas provincias han hecho del uso del cianuro y otras sustancias, con el fin de proteger el agua y el ambiente, como analizaremos infra en torno a las Leyes complementarias, Ley $N^{\circ} 5.001$, de 2003, de Chubut; Ley $N^{\circ} 7.879$, de 2007, de Tucumán; Ley N².349, de 2007, de La Pampa; Ley Nº 9.526, de 2008, de Córdoba; Ley N 634, de 2008, de San Luis; Ley $N^{\circ} 853$, de 2011, de Tierra del Fuego; y Ley N 7.722, de 2007, de Mendoza.

\section{La Ley de presupuestos mínimos de protección de glaciares y sus antecedentes}

El 30 de septiembre de 2010 el Congreso de la Nación sancionó la Ley $N^{\circ} 26.639$, de 2010, estatuyendo los presupuestos mínimos de protección de glaciares y ambiente glacial, concluyendo el arduo camino que tal precepto demandó.

El errático itinerario de la Ley $N^{\circ} 26.639$, de 2010, comienza con la aprobación, por unanimidad por ambas cámaras del Congreso de la Nación, de la Ley $N^{\circ} 26.418$, que pretendió regular inicialmente tal temática, y el sorprendente veto presidencial posterior que, por Decreto del Poder Ejecutivo Nacional N 1.837, de 2008, observó en forma integral tal norma, fundándose en el rechazo sustancial de tres de sus artículos (6, 7 y 15).

Con posterioridad, la reiteración de las iniciativas sobre la temática llevó a que entre dos proyectos sometidos a votación en la Cámara de Diputados, finalmente terminara siendo aprobado -por 35 votos contra 33- el texto más protectorio del ambiente, en una lógica de alineación política ciertamente compleja que dejó de lado partidos políticos, procedencias ideológicas y geográficas ${ }^{4}$.

\footnotetext{
2 Sobre la conflictividad minero-ambiental en Argentina desde una perspectiva jurídica, ver PINTO 2012a, 239.

3 Los esquemas de regulación ambiental de la actividad minera los hemos expuesto en PINTO 1999, 1.

4 Desde una óptica, la legislación constituye una abstracción racional independizada de sus condiciones de producción, pero a la vez, no constituye sino el resultado de un conflicto de intereses que en un sistema representativo, republicano y democrático distintos sujetos canalizan a través de su influencia en la institución parlamentaria, y que no puede ser escindida de su contexto de producción. Como apunta Kelsen: "Todo conflicto jurídico es, por cierto, un conflicto de intereses, es decir, un conflicto de poder; toda disputa jurídica es consecuentemente una controversia política, y todo conflicto que sea caracterizado como conflicto político o de intereses o de poder puede ser resuelto como controversia jurídica" (KELSEN 1995, 21). Este razonamiento pone en duda, no solo la consistencia, sino tan solo el sentido de algunas conclusiones dirigidas a argumentar la
} 
Con la promesa presidencial de no reiterar el veto, el Régimen de Presupuestos Mínimos para la Preservación de los Glaciares y del Ambiente Periglacial (Ley $N^{\circ} 26.639$, de 2010), fue finalmente promulgado y publicado en el Boletín Oficial el día 28 de octubre de 2010 (en adelante, indistintamente, Ley de protección de glaciares) ${ }^{5}$.

\section{La conflictividad en torno a la tutela glacial: minería y judiciali- zación de la Ley $\mathrm{N}^{\circ} 26.639$, de 2010}

El curso de los acontecimientos, y las tensiones sociales que se han manifestado en ellos, hace que sea inevitable que apreciemos la vinculación entre las normas de tutela de glaciares y la actividad minera existente en las áreas de montaña.

Sin pretender desconocer los diversos beneficios que generab, tampoco puede obviarse que la minería ha resultado desde siempre una actividad de alto impacto ${ }^{7}$. Pero en los años recientes, los aspectos negativos han tomado trascendencia y se ha constituido en el eje de diversos movimientos sociales que la cuestionan desde un discurso ambientalista ${ }^{8}$, aunque también con significancias éticas, sociales y económicas 9 .

Sin que pueda establecerse una clara delimitación, existe sin dudas una relación tangible entre los referidos movimientos y el sustrato ideológico que dio lugar a la formación de la Ley $N^{\circ} 26.639$, de 2010, de presupuestos mínimos para la preservación de los glaciares y del

\footnotetext{
inconstitucionalidad de normas ambientales de protección: "...Las normas provinciales que expresamente prohíben técnicas de extracción de minerales son discriminatorias y es evidente su objetivo político y no jurídico" (CASTRILLO 2010, 1089).

5 Sobre la sanción de esta norma, se recomienda ver CATALANO y GARCÍA TORRES 2010, 714; Di Paola 2010, 723; Alonso 2010, 1; Catalano y García Torres 2009, 1; Gerosa Lewis 2010, 403; Rodríguez 2011, 1.

6 Nadie podría razonablemente renegar sin más contra la actividad minera, ya que como explica acabadamente MARTínEz 2010, 19 y ss., la misma es una actividad de importancia indispensable para la sociedad en que vivimos: el arte, las viviendas, las comunicaciones, la vestimenta y los utensilios cotidianos en su generalidad, los vehículos y los caminos que los contienen, las naves que hacen el transporte de personas y mercaderías, los fármacos, tecnologías y prótesis medicinales, la generación y transporte de energía, las restantes industrias, e incluso el sistema monetario; todo ello -y seguramente más- depende en mayor o menor medida de la actividad minera.

7 VALLS 1981, 20; explica que la actividad minera deteriora sensiblemente el ambiente, ya que las excavaciones destruyen el suelo o provocan su hundimiento, lo que afecta el curso de las aguas; sus desechos contaminan agua y atmósfera y cubren grandes extensiones.

8 Sobre los conflictos y movilizaciones socioambientales que cuestionan la actividad minera en Argentina, WAGNER 2011.

9 DOBSON 1998, 3 y ss.; explica que aunque en ciertas oportunidades este tipo de conflictos se enfocan en términos de "justicia ambiental", en realidad no tratan de una justicia por el ambiente per se, sino como una reclamación ante la injusticia en la distribución de costos y beneficios de las actividades contaminantes.
} 
ambiente periglacial, así como otras normas vinculadas a la tutela del agua. No solo porque dicha Ley dispone expresamente que en dichos ámbitos queda prohibida -en particular- la exploración y explotación minera e hidrocarburíferas, sino además porque según han sostenido sus principales promotores, tal norma es una reacción ante el nuevo tipo de minería existente en nuestro país, ya que anteriormente no se producían explotaciones a más de $4.000 \mathrm{~m}$ de altura, donde se encuentran los glaciares andinos, y ante esta nueva realidad fue necesario readecuar el marco legal ${ }^{10}$.

En este sentido, aunque quienes han promovido activamente el régimen de preservación de glaciares afirman que tal regulación no impide el desarrollo de la actividad minera salvo en una porción menor del territorio $^{11}$, evidentemente no existe consenso en tal opinión, posiblemente porque es justamente en las áreas que alcanza el ambiente periglacial donde se sitúan diversos yacimientos de importancia económica.

El conflicto se ha marcado en este aspecto mediante diversas vertientes, que incluyen primeramente el ya referido veto de un previo intento de dictar un régimen de presupuestos mínimos en la materia con motivos vinculados al impacto que la norma ocasionaba en el desarrollo económico regional12; y luego el dictado de normas provinciales complementarias que en algunos casos presentan cierta tensión e incluso posibles contradicciones indebidas con la Ley $\mathrm{N}^{\circ} 26.639$, de $2010^{13}$, y en otros -como hemos referido supra- refuerzan su esquema protectorio y así dificultan la actividad minera mediante la prohibición de sustancias de importante riesgo ambiental.

Esta última tendencia se refleja en la legislación de provincias, como Chubut (Ley $N^{\circ}$ 5.001, de 2003, que prohíbe la actividad minera metalífera en la modalidad cielo abierto y la utilización de cianuro en los procesos de producción minera ${ }^{14}$ ), Tucumán (Ley $N^{0} 7.879$, de 2007, que prohíbe la actividad minera metalífera en la modalidad cielo abierto y la utilización de cianuro y mercurio en los procesos de producción minera), La Pampa (Ley $N^{\circ} 2.349$, de 2007, que prohíbe la utilización de cianuro, mercurio, ácido sulfúrico y toda sustancia química conta-

\footnotetext{
10 Villalonga 2011, 275.

11 Di PAOLA 2011, 28; expresa que el hecho de que solo el 1\% del territorio argentino es ocupado por áreas glaciares y periglaciares objeto de protección, no representa en modo alguno un obstáculo para el desarrollo de las actividades productivas en el resto del territorio. 12 En este sentido, ver las fundamentaciones expuestas en el Decreto 1837, de 2008 del Poder Ejecutivo Nacional.

13 Di PAOLA 2011, 28-31, analiza este tema en relación a las Leyes (Ley Provincial Salta $N^{\circ}$ 7.625, de 2010; Ley Provincial La Rioja N 8.773, de 2010; Ley Provincial San Juan Nº 8.144, de 2010; y Ley Provincial Jujuy N 5.647, de 2010).

14 Sobre esta norma y su validez, ver fallo, Villivar con Provincia del Chubut y otros (2007).
} 
minante en el proceso de cateo, prospección, extracción, explotación, tratamiento $\mathrm{y} / \mathrm{o}$ industrialización de minerales metalíferos, como así también la explotación minera de minerales metalíferos a cielo abierto), Córdoba (Ley $N^{\circ}$ 9.526, de 2008, que prohíbe la minería metalífera a cielo abierto; la actividad minera de minerales nucleares en todas sus etapas; y el uso en actividades de minería metalífera de cianuro, cianuro de sodio, bromuro de sodio, yoduro de sodio, mercurio, ácido sulfúrico, ácido clorhídrico, ácido fluorhídrico, ácido nítrico y toda otra sustancia química contaminante, tóxica o peligrosa incluida en la Ley $\mathrm{N}^{\circ} 24.051$ y normas concordantes), San Luis (Ley N 634, de 2008 que prohíbe el uso de sustancias químicas en los procesos mineros metalíferos, destacando la prohibición de cianuro, cianuro de sodio, bromuro de sodio, yoduro de sodio, mercurio, ácido sulfúrico, ácido clorhídrico, ácido fluorhídrico, ácido nítrico, amonio y carbonato) y Tierra del Fuego (Ley $N^{\circ} 853$, de 2011, que prohíbe la minería a cielo abierto y el uso de sustancias contaminantes que identifica) ${ }^{15}$.

Dentro de estas normas se encuentra, además, la Ley $N^{\circ} 7.722$, de 2007, de la provincia de Mendoza. La Ley mendocina dispone sin más: "A los efectos de garantizar debidamente los recursos naturales con especial énfasis en la tutela del recurso hídrico, se prohíbe en el territorio de la Provincia de Mendoza, el uso de sustancias químicas como cianuro, mercurio, ácido sulfúrico, y otras sustancias tóxicas similares en los procesos mineros metalíferos de cateo, prospección, exploración, explotación y/o industrialización de minerales metalíferos obtenidos a través de cualquier método extractivo" (art. 1 Ley N 7.722, de 2007). Hemos expresado en relación a la génesis de esta norma que la misma presenta causas que exceden la mera preocupación ambiental e incorporan otras tensiones y valores sociales ${ }^{16}$, incluso reaccionarios a las

\footnotetext{
15 También integraron momentáneamente esta tendencia las provincias de Río Negro (Ley Provincial Río Negro N³.981, de 2005); y La Rioja (Ley Provincial La Rioja N 8.137, de 2007). Sin embargo, tales exigencias fueron luego dejadas sin efecto.

16 En este sentido, se sostuvo que: "algo que nos parece fundamental para la comprensión de la génesis de la normativa [de la Ley $N^{\circ} 7.722$ ], y refiere a que, aunque a primera vista la dialéctica del conflicto pudiera entenderse entablada entre el desarrollo económico minero y la preservación del medio ambiente representada en "el agua" como recurso, ello constituye a nuestro juicio una simplificación excesiva, y una inteligencia limitada e ingenua del asunto. Ello así porque la disputa puede ser leída de manera más real que aparente, ya no tanto en defensa de un interés "ambiental" abstracto y ciertamente retórico, sino entre dos modelos de desarrollo económico con diversas implicancias ambientales. En efecto, y a nuestro juicio como anticipamos en el título, en gran medida se trató de una disputa "por el agua", entre los sectores agrícola productivos tradicionales con fuerte arraigo en la cultura e idiosincrasia de Mendoza que -además de ver amenazada la calidad de las aguas, vieron fundamentalmente amenazados los volúmenes-, y el uso minero, que requería de ingentes cantidades del mismo líquido, siempre escaso en la provincia. El modelo de desarrollo agrícola tradicional encontró así, en la causa ambiental un discurso con fuerte aceptación popular y en los ambientalistas, un aliado estratégico en la
} 
tendencias normativas previas que buscaban facilitar el desarrollo minero en descuido de los valores ambientales y sociales ${ }^{17}$.

A este esquema de conflicto entre la actividad minera y el régimen de tutela del agua y los cuerpos glaciares, se suma un proceso judicial donde desde el sector minero -empresarial y gremial- se plantea la inconstitucionalidad de la Ley $N^{\circ} 26.639$, de 2010. En ese proceso judicial, el 2 de noviembre de 2010 se dispuso cautelarmente la suspensión de los arts. 2, 3, 5, 6, 7 y 15 de la Ley $N^{\circ} 26.639$, de 2010, en el territorio de la Provincia de San Juan hasta tanto se resuelva la cuestión de fondo planteada, relativa a la inconstitucionalidad y nulidad de la Ley ${ }^{18}$; similar resolución fue otorgada en las causas Minera Argentina Gold S.A. con Estado Nacional (2012) y Barrick Exploraciones Argentinas S.A. y otro con Estado Nacional (2012).

Sin embargo, posteriormente tales medidas cautelares fueron dejadas sin efecto por la Corte Suprema de Justicia mediante sendos resolutivos emitidos el 3 de julio de 2012 en dichas causas, por entender que tales medidas eran autocontradictorias, no cumplían con los requisitos mínimos exigibles a toda medida cautelar, y podían impactar en el principio republicano de división de poderes ${ }^{19}$, sin que a la fecha exista una resolución sobre el fondo del asunto en discusión.

\section{Principales cuestiones controvertidas en torno a la Ley $\mathrm{N}^{\circ}$ 26.639, de 2010}

1. Objeto

La Ley $N^{\circ}$ 26.639, de 2010, dejando en claro que tiene por objeto su preservación como reservas estratégicas de recursos hídricos para el consumo humano; para la agricultura y como proveedores de agua para la recarga de cuencas hidrográficas; para la protección de la biodiver-

disputa por el recurso en cuanto importaba preservar el statu quo, por sobre la novedosa, pero demonizada actividad minera" (MARTIN 2008, 607).

17 En PINTO 2008, 174; calificamos a la Ley $N^{\circ}$ 7.722, de 2007, como una reacción normativa generada por el tema minero-ambiental ante una seguidillas de normas contradictorias, muchas de las cuales reflejaban políticas que promovían la actividad por sobre los niveles de tutela ambiental.

18 Ver fallo A.O.M.A. y otras con Estado Nacional (2010). Gil Domínguez, criticando los fundamentos del fallo, concluye: "La construcción del discurso jurídico sobre el hoy (que se aprovecha de las necesidades del trabajador contando con la complicidad de los supuestos representantes de los trabajadores) deja de lado los intentos de garantizar una futuridad, en una mirada posada más allá de la propia existencia, que emerge de los principios que regulan la protección del ambiente" (GIL DomíngUEZ 2010, 236). Ver también la nota crítica de UGARTE 2011, 171.

19 Para un análisis de estos pronunciamientos, Vid. GonZÁlez RodríGUeZ y Zonis 2012, 545. 
sidad; como fuente de información científica y como atractivo turístico (art. 1 Ley $\mathrm{N}^{\circ}$ 26.639, de 2010).

Dentro de la doctrina, se ha sostenido sin embargo que el objeto de esta norma trasciende la mera tutela de los recursos hídricos, para avanzar hacia aspectos propios de las acciones de seguimiento y adaptabilidad al cambio climático ${ }^{20}$.

Más allá de estas consideraciones doctrinarias, debemos observar que en el objeto definido legalmente existe una línea muy sutil entre el contenido de protección al que deben limitarse las normas de presupuestos mínimos y otros contenidos que -por referir al uso del recursoresponden a las potestades reservadas en las provincias ${ }^{21}$.

Si bien la referencia a reservas para usos o explotación turística arroja un halo inconvenientes al objeto de regulación que el art. 41 $\mathrm{CN}$ autoriza a la norma nacional, el contenido de la Ley $\mathrm{N}^{\circ} 26.639$, de 2010, se consolida en torno a disposiciones protectorias más que de explotación. Con ello, el alcance del objeto regulatorio debe atenderse contextualizando el art. 1 de la Ley N²6.639, de 2010, junto a los restantes institutos que la norma contempla para su consecución.

\section{2. Ámbito de protección}

La protección se extiende al ámbito glaciar definida como: toda masa de hielo perenne estable o que fluye lentamente, con o sin agua intersticial, formado por la recristalización de nieve, ubicado en diferentes ecosistemas, cualquiera sea su forma, dimensión y estado de conservación. Son parte constituyente de cada glaciar el material detrítico rocoso y los cursos internos y superficiales de agua (art. 2 Ley N²6.639, de 2010).

Pero también, con mayor polémica, el ámbito se extiende al ambiente periglacial, entendiendo por tal, en alta montaña, al área con suelos congelados que actúa como regulador del recurso hídrico; y en la media y baja montaña al área que funciona como regulador de recursos hídricos con suelos saturados en hielo.

A partir de estas definiciones, queda claro que el problema central es la identificación de estas zonas en el territorio, especialmente en el caso del ambiente periglacial, lo que deberá efectuarse a través del inventario cuya realización prevé perentoriamente la Ley N²6.639, de 2010.

\footnotetext{
20 Rodríguez Salas 2011.

21 Como hemos reseñado en PINTO 2012b, 384; la delegación regulatoria efectuada en el art. $41 \mathrm{CN}$ a favor de la autoridad nacional no ha sido realizada hacia toda la materia ambiental, sino limitada a las normas que contengan presupuestos "de protección". Los aspectos que exceden la tutela ecosistémica y avancen en la explotación económica están excluidos del poder de policía nacional.
} 
Y a la resulta de tal zonificación, es posible que la polémica referida -que actualmente se circunscribe a la conflictividad y judialización planteada en relación a la actividad minera- en el futuro se extienda a otros aspectos en función de las actividades e infraestructuras prohibidas que queden ubicadas en dichos ámbitos. En este sentido, existen numerosas obras de infraestructuras que probablemente resulten alcanzadas por las prohibiciones que contempla la Ley $N^{\circ} 26.639$, de 2010 -las que detallamos infra-, aunque actualmente no se perciban en los análisis cotidianos: centros de esquí, caminos locales y rutas internacionales, villas de alta montaña, centros aduaneros, gasoductos, etc.

\section{Inventario}

La Ley $N^{\circ}$ 26.639, de 2010, crea el Inventario Nacional de Glaciares, donde se individualizarán todos los glaciares y geoformas periglaciares que actúan como reservas hídricas existentes en el territorio nacional con toda la información necesaria para su adecuada protección, control y monitoreo.

El Inventario Nacional de Glaciares deberá contener la información de los glaciares y del ambiente periglacial por cuenca hidrográfica, ubicación, superficie y clasificación morfológica de los glaciares y del ambiente periglacial y deberá actualizarse con una periodicidad no mayor de cinco (5) años, verificando los cambios en superficie, su estado de avance o retroceso y otros factores que sean relevantes para su conservación (art. 4).

La trascendencia de la realización del referido inventario es puesta de manifiesto por Di Paola y Duverges, quienes señalan que la importancia fundamental de la realización del Inventario Nacional de Glaciares radica en que es el instrumento en el que se sentarán las bases para definir el estado actual de las reservas hídricas cordilleranas, las interacciones de los cuerpos de hielo con otros sistemas naturales y los posibles impactos de los cambios climáticos futuros sobre dichos recursos estratégicos. Por otra parte, la información registrada en el inventario será una herramienta fundamental para la identificación y delimitación de las zonas protegidas en el marco de la Ley $\mathrm{N}^{\circ} 26.639$, de $2010^{22}$.

\section{Autoridades competentes}

La competencia es uno de los puntos más álgidos de la Ley $N^{\circ} 26.639$, de 2010, que se enmarca en el irresuelto y conflictivo esquema constitucional de distribución federal de competencias que legó la $\mathrm{CN}$, en cuanto incorporó competencias y títulos de intervención cruzados, cuyos límites son claramente forzados en numerosas normas nacionales,

22 Di Paola y Duverges 2012, 547. 
aunque aún no han sido aún delineados en forma clara por la autoridad judicial ${ }^{23}$.

Entre otras competencias y títulos que colisionan para el caso, particular relevancia resulta la superposición del título dominial originario de los recursos naturales que se reconoce en forma expresa a las provincias (art. $124 \mathrm{CN}$ ) con la competencia nacional para la sanción de la Leyes de presupuesto mínimos de protección ambiental (art. $41 \mathrm{CN}$ ) en virtud de la cual se dicta la Ley $N^{\circ} 26.639$, de 2010.

En este marco la Ley $\mathrm{N}^{\circ}$ 26.639, de 2010 instituye como "autoridad competente" aquella que determine cada jurisdicción, vale decir las provincias salvo que se trate de áreas protegidas comprendidas por la Ley N ${ }^{\circ} 22.351$, de 1980, donde la autoridad competente será la Administración de Parques Nacionales. Sin embargo, Ley $N^{\circ} 22.351$, de 1980 también estatuye una "autoridad de aplicación", determinando que la misma será el organismo nacional de mayor nivel jerárquico con competencia ambiental, hoy la Secretaría de Ambiente y Desarrollo Sustentable de la Nación, a la que se le asignan específicas funciones ${ }^{24}$.

Indudablemente, la norma acude en este aspecto a una forzada distinción entre unas competencias innominadas y otras que denomina "de aplicación", buscando burlar las limitaciones constitucionales que existen en la materia ${ }^{25}$.

\footnotetext{
${ }^{23}$ A pesar de la fuerte crítica doctrinaria que existe desde esta perspectiva a numerosas normas de presupuestos mínimos, no ha existido hasta ahora un resolutivo judicial que arroje luz al alcance del derecho. El único proceso iniciado en este sentido -Mendoza, Provincia de con Estado Nacional (2009)- fue desechado formalmente por considerarse que se trataba de un planteo abstracto que no habilitaba la expresión judicial.

24 Serán funciones de la autoridad nacional de aplicación: a) Formular las acciones conducentes a la conservación y protección de los glaciares y del ambiente periglacial, en forma coordinada con las autoridades competentes de las provincias, en el ámbito del Consejo Federal de Medio Ambiente (COFEMA), y con los ministerios del Poder Ejecutivo nacional en el ámbito de sus respectivas competencias; b) Aportar a la formulación de una política referente al cambio climático acorde al objetivo de preservación de los glaciares y el ambiente periglacial, tanto en la órbita nacional, como en el marco de los acuerdos internacionales sobre cambio climático; c) Coordinar la realización y actualización del Inventario Nacional de Glaciares, a través del Instituto Argentino de Nivología, Glaciología y Ciencias Ambientales (IANIGLA); d) Elaborar un informe periódico sobre el estado de los glaciares y el ambiente periglacial existentes en el territorio argentino, así como los proyectos $O$ actividades que se realicen sobre glaciares y el ambiente periglacial o sus zonas de influencia, el que será remitido al Congreso de la Nación; e) Asesorar y apoyar a las jurisdicciones locales en los programas de monitoreo, fiscalización y protección de glaciares; f) Crear programas de promoción e incentivo a la investigación; g) Desarrollar campañas de educación e información ambiental conforme los objetivos de la presente Ley; h) Incluir los principales resultados del Inventario Nacional de Glaciares y sus actualizaciones en las comunicaciones nacionales destinadas a informar a la Convención Marco de Naciones Unidas sobre Cambio Climático. (art. 10 Ley № 22.351, de 1980).

${ }^{25} \mathrm{El}$ mismo art. $41 \mathrm{CN}$ al disponer la potestad nacional de dictar normas de presupuestos mínimos expresa que ello es sin que aquellas alteren la jurisdicción local. Por ello GeLLI
} 
Finalmente, este mismo exceso se produce en cuanto la Ley $\mathrm{N}^{\circ}$ 26.639, de 2010 confía la realización del inventario y monitoreo del estado de los glaciares y del ambiente periglacial al Instituto Argentino de Nivología, Glaciología y Ciencias Ambientales (en adelante, IANIGLA) aunque con la coordinación de la autoridad nacional de aplicación, circunstancia que naturalmente ha motivado la queja de las jurisdicciones locales.

La Ley $N^{\circ} 26.639$, de 2010 agrega además que cuando se trate de zonas fronterizas pendientes de demarcación del límite internacional previo al registro del inventario, se dará intervención al Ministerio de Relaciones Exteriores, Comercio Internacional y Culto.

5. Regulación de actividades prohibidas, sujetas a evaluación y en ejecución

La Ley regula o limita la realización de distinto tipo de actividades en el ámbito de aplicación de la misma, a saber:

a) Actividades prohibidas. En esta agrupación de actividades prohibidas se puede distinguir que por un lado se fija un estándar, un principio prohibitivo; y por otro se establecen prohibiciones específicas. En cuanto al principio, se fija la prohibición general de toda actividad que vulnere el objeto de la misma Ley, esto es la protección y preservación de los glaciares así como de los ambientes periglaciales; y las que implique la destrucción, traslado o interfieran en el avance de los glaciares.

En lo que se refiere a las prohibiciones específicas el texto de la Ley $\mathrm{N}^{\circ}$ 26.639, de 2010 (art. 4) incluye:

i) Sustancias contaminantes: se prohíbe la liberación, dispersión o disposición de sustancias o elementos contaminantes, productos quími-

2001, 32; explica que si bien el Congreso dicta la normativa ambiental mínima para todo el país, su aplicación administrativa o jurisdiccional corresponde a los gobiernos locales, con lo que dentro de cada jurisdicción local las responsabilidades de las provincias son primarias y fundamentales para aplicar la normativa legal. En este sentido se ha manifestado el máximo Tribunal nacional en Roca, Magdalena con Buenos Aires, Provincia de (1995); donde sostuvo que siendo preponderante en la causa la materia ambiental, "ello trae aparejado que sean las autoridades administrativas y judiciales del Estado de la Provincia de Buenos Aires las encargadas de valorar si la obra proyectada afecta aspectos tan propios del derecho público provincial, como lo es todo lo concerniente a la protección del medio ambiente. En efecto, corresponde a las autoridades locales la facultad de aplicar los criterios de protección ambiental que consideren conducentes para el bienestar de la comunidad que gobiernan, como así mismo valorar y juzgar si los actos que llevan a cabo sus autoridades, en ejercicio de poderes propios, afectan el bienestar perseguido. Tal conclusión cabe extraerla de la propia Constitución, la que, si bien establece que le cabe a la Nación 'dictar las normas que contengan los presupuestos mínimos de protección', reconoce expresamente las jurisdicciones locales en la materia, las que no pueden ser alteradas (art. 41, tercer párrafo $\mathrm{CN})^{\prime \prime}$. 
cos o residuos de cualquier naturaleza o volumen. Se hace extensiva al ambiente periglacial.

ii) Construcción: se prohíbe la construcción de obras de arquitectura o infraestructura, excepto las necesarias para la investigación científica y las prevenciones de riesgos.

iii) Minería e hidrocarburos: se prohíbe la exploración y a explotación minera e hidrocarburífera; se hace, también, extensivo al ambiente periglacial.

iv) Industria: se prohíbe la instalación de industrias o desarrollo de obras o actividades industriales.

Esta prohibición absoluta de algunas actividades es sin lugar a dudas la que ha sido objeto de los mayores cuestionamientos, tanto en cuanto excede la naturaleza de "presupuesto mínimo"26; como por afectar derechos constitucionales -como el ejercicio de toda industria lícita y el derecho al trabajo-, lo que ha sido atendidos entre los fundamentos de las resoluciones cautelares que antes hemos referido en relación a la suspensión de la aplicación de la Ley N4.392, de 1978, en la provincia de San Juan.

b) Actividades sujetas a evaluación. Aquellas actividades que no se encuentran prohibidas deben realizar un doble proceso de evaluación, antes de la autorización y ejecución de las mismas. En primer lugar una evaluación de impacto ambiental. La segunda es una evaluación ambiental de estrategia ${ }^{27}$.

\footnotetext{
26 Sobran sin embargo ejemplos de normas de presupuestos mínimos de protección ambiental vigentes y en proceso de implementación que prohíben el desarrollo de determinadas actividades, o su instalación en determinados sitios o el uso de ciertos elementos o sustancias a saber:

a) Ley $N^{\circ}$ 25.670, de 2002: en esta norma se establece la prohibición de ingreso al país de PCBs, de equipos que los contengan, y las actividades de producción, comercialización y reposición en equipos en uso.

b) Ley $\mathrm{N}^{\circ}$ 25.916, de 2004: establece que los centros de disposición final deberán ubicarse en sitios suficientemente alejados de áreas urbanas, sumando la prohibición de su emplazamiento en dentro de áreas protegidas o sitios que contengan elementos significativos del patrimonio natural y cultural, como también en sitios inundables.

c) Ley $\mathrm{N}^{\circ}$ 26.331, de 2007: prohibió los desmontes durante el plazo de Ordenamiento Territorial Ambiental del bosque nativo; prohíbe los desmontes en las áreas clasificadas como Categorías I (rojo) y II (amarillo); prohíbe la quema a cielo abierto de los residuos derivados de desmontes o aprovechamientos sostenibles, y finalmente expresamente requiere la realización del procedimiento de EIA en los términos de la Ley General del Ambiente con amplia participación ciudadana mediante audiencias y consultas públicas y el adecuado y previo acceso a la información pública ambiental.

d) Ley $N^{\circ}$ 26.562, de 2009: establece la prohibición de toda actividad de quema que no cuente con la debida autorización, la cual solo puede otorgarse en el marco del cumplimiento de condiciones específicas.

27 A diferencia de la Evaluación de Impacto Ambiental, que presenta un régimen básico en la Ley $N^{\circ} 25.675$, de 2002, y normas complementarias que la desarrollan en la gene-
} 
En estas instancias evaluativas se garantiza la participación ciudadana, especialmente a través de audiencias, de acuerdo a la Ley $\mathrm{N}^{\circ}$ 25.675, de 2002, norma que específicamente en su artículo 21 sostiene que "la participación ciudadana deberá asegurarse, principalmente, en los procedimientos de evaluación de impacto ambiental y en los planes y programas de ordenamiento ambiental del territorio, en particular, en las etapas de planificación y evaluación de resultados".

Finalmente, la Ley $\mathrm{N}^{\circ} 26.639$, de 2010, exceptúa del proceso de evaluación (art. 7) a las actividades de: 1) Rescate, derivado de emergencias; 2) Científicas, realizadas a pie o sobre esquíes, con eventual toma de muestras, que no dejen desechos en los glaciares y el ambiente periglacial; 3) Deportivas, incluyendo andinismo, escalada y deportes no motorizados que no perturben el ambiente.

c) Actividades en ejecución. En los casos en que se estén ejecutando actividades prohibidas, las mismas deben someterse a una auditoría ambiental en la que se identifiquen y cuantifiquen los impactos ambientales potenciales y generados, en un plazo de ciento ochenta días. Si se verifica que hay un impacto relevante las autoridades dispondrán las medidas pertinentes para que se cumpla la presente Ley $N^{\circ} 26.639$, de 2010, pudiendo ordenar el cese o traslado de la actividad y las medidas de protección, limpieza y restauración que correspondan (art. 15 Ley $\mathrm{N}^{\circ}$ 26.639, de 2010).

Esta disposición plantea una contradicción interna en la Ley $\mathrm{N}^{\circ}$ 26.639, de 2010, ya que a la vez que prohíbe ciertas actividades sin posibilidad de excepción, contempla que esas mismas actividades si están siendo ejecutadas deben ser evaluadas y valoradas, lo que genera un estatus irrazonable de diferenciación entre dichas situaciones. Si existen actividades que deben ser prohibidas más allá de todo análisis, entonces nada cambia si estas se iniciaron antes de la vigencia de la Ley $\mathrm{N}^{\circ}$ 26.639, de 2010; y si esas actividades son susceptibles de continuar en caso de que exista una evaluación favorable, entonces es irrazonable su prohibición absoluta.

\section{Régimen sancionatorio}

Las infracciones y sanciones serán las fijadas por las provincias competentes para la aplicación de la Ley $N^{\circ} 26.639$, de 2010, sin perjuicio del

ralidad de las provincias, la Evaluación Ambiental Estratégica es un instituto que carece de desarrollo procedimental, lo que merma su eficacia. Reglamentariamente, el Decreto del Poder Ejecutivo Nacional N²07, de 2011, expresa en su art. 7 que se entiende por Evaluación Ambiental Estratégica aquel proceso sistemático de estudio de impactos ambientales de las políticas, planes o programas y de sus alternativas, incluyendo la preparación de un informe escrito y las conclusiones de la evaluación y su uso en los procesos de decisiones públicas, mas no brinda pauta alguna de contenido procedimental. 
carácter mínimo y supletorio que reviste el régimen sancionatorio estipulado en la Ley $\mathrm{N}^{\circ} 26.639$, de 2010. Esto implica que los regímenes provinciales podrán superar pero no bajar los parámetros establecidos por el régimen básico, el que solo resultará de aplicación ante la ausencia o imprevisión de régimen local ${ }^{28}$.

Así, como sanciones básicas prevé las de: i) Apercibimiento; ii) Multa de cien (100) a cien mil (100.000) sueldos básicos de la categoría inicial de la administración pública nacional; iii) Suspensión o revocación de las autorizaciones. La suspensión de la actividad podrá ser de treinta (30) días hasta un (1) año, según corresponda y atendiendo a las circunstancias del caso; y iv) Cese definitivo de la actividad.

La Ley $N^{\circ}$ 26.639, de 2010 considera reincidente (art. 12) al que dentro del término de cinco (5) años anteriores a la fecha de comisión de la infracción haya sido sancionado por otra infracción de causa ambiental, motivo por el cual las multas y la suspensión/revocación y los mínimos y máximos pueden triplicarse.

En lo que atañe a la responsabilidad, el texto legal esboza que en el caso de que una persona jurídica fuera la infractora los que estén a cargo de la dirección o gerencia serán solidariamente responsable de sanciones. En cuanto al destino de lo percibido en conceptos de multas se focalizarán en la protección y restauración ambiental de los glaciares afectados.

\section{Conclusiones}

$1^{\circ} \mathrm{El}$ derecho constitucional ambiental argentino favorece altos niveles de indefinición y conflictividad, debido a que mientras a la Nación se le asigna la competencia para la sanción de normas con injerencia directa -leyes de presupuestos mínimos de protección ambiental- o indirecta -Código de Minería- en la temática, las provincias complementan estas últimas y retienen la actividad jurisdiccional; y además mantienen como poderes no delegados los aspectos que hacen a la regulación de usos, y detentan el dominio originario de los recursos naturales existentes en su territorio y su consiguiente disposición.

Lamentablemente, en ese escenario no es extraño que el contenido de ciertas normas nacionales genere tensiones en torno a las potestades delegadas y no delegadas, dándose lugar a una falta de certeza que resta considerable eficacia a las normas de presupuestos mínimos. En el caso de la Ley N²6.639, de 2010 tales tensiones implican ciertos forzamientos competenciales que resultan claramente cuestionables.

${ }^{28}$ PINTO 2013, 13. 
$2^{\circ}$ Por otra parte, la Ley $N^{\circ} 26.639$, de 2010 se suma al complejo sistema que regula los cursos de aguas, y por ello vale tener en cuenta que esta, como el resto de la regulación nacional y provincial respectiva, resulta de plena aplicación, como muy bien ha determinado la Corte Nacional en los procesos que cuestionaban la misma desde la defensa de los intereses mineros.

$3^{\circ}$ Los principales aportes de la Ley $N^{\circ} 26.639$, de 2010 refieren a distintos y variados aspectos.

a) La confirmación de los glaciares como bienes del dominio público es uno de ellos, calificación que no se hace extensiva sin embargo al ambiente periglacial.

b) La prohibición de determinadas actividades en áreas específicas, tal como realiza la norma analizada, es una técnica común del derecho administrativo y ambiental, como lo demuestran otras leyes de PMPA, sin que pueda ab initio reputarse como inconstitucional per se. Sin lugar a dudas, la razonabilidad de la prohibición jugará un papel preponderante en los conflictos que se presenten.

c) Es meritorio, pero de dudosa constitucionalidad, la delegación de la ejecución del inventario a un organismo científico nacional -IANIGLA- bajo coordinación de la autoridad nacional, o el otorgamiento de funciones a la misma como "autoridad de aplicación", en conflicto con la existencia de autoridades locales competentes que reconoce la misma norma.

d) La auditoría ambiental prevista para las actividades en curso, autorizadas bajo otro régimen jurídico previo, será fuente de inevitables conflictos, especialmente por la contradicción que genera la tolerancia de tales actividades a pesar de existir -al menos desde el texto legal- una prohibición general sobre ellas.

e) Otro punto destacable es la instauración de un doble proceso de evaluación (EAE y EIA) para actividades no prohibidas, con necesaria participación pública y de un régimen sancionatorio común que puede -sin embargo- ser fácilmente desvirtuado en su reglamentación y aplicación por las autoridades locales. Todas estas instituciones resultan instrumentos de gestión esenciales para el futuro cumplimiento de los objetivos perseguidos por la Ley $\mathrm{N}^{\circ} 26.639$, de 2010.

$4^{\circ}$ Las conflictivas tensiones $-y$ su configuración en los estamentos del poder público- puestas de manifiesto durante el trámite de sanción y promulgación de la Ley $N^{\circ} 26.639$, de 2010, se ha mantenido luego de su sanción. Así, los avances y retrocesos que -en un primer momento- implicaron la sanción y veto de la regulación, adoptan en la actualidad forma de procesos judiciales, donde las medidas precautorias y 
su revocación continúan manifestando la fuerte puja entre los intereses sociales en juego.

\section{Bibliografía citada}

Alonso, Julio Santiago (2010): “¿De qué trata el Régimen de Presupuestos Mínimos para la Preservación de los Glaciares y del Ambiente Periglacial?" en: La Ley. Suplemento Actualidad (Buenos Aires, Thomson-La Ley), p. 1.

Castrillo, Carlos V. (2010): "Leyes provinciales que prohíben ciertas técnicas de extracciones de minerales" en: La Ley (Buenos Aires, Thomson-La Ley), T² 2010-A, p. 1089.

Catalano, Mariana y García Torres, Mariana (2009): "Comentario al veto sobre el proyecto de ley de protección de glaciares" en: La Ley. Suplemento Actualidad (Buenos Aires, Thomson-La Ley), p. 1.

(2010): "Finalmente: La ley de glaciares" en: La Ley (Buenos Aires, Thomson-La Ley), T²010-F, p. 714.

Dı PAOLA, María Eugenia (2010): "La protección de los glaciares" en: La Ley (Buenos Aires, Thomson-La Ley), T²010-F, p. 723.

(2011): "La nueva ley de protección de los glaciares y el ambiente periglacial" en: Revista del Foro de Cuyo (Mendoza, Dike), pp. 15-34.

DI PAOLA, María Eugenia y Duverges, Dolores María (2012): "Minería, participación y ley de glaciares" en: La Ley (Buenos Aires, Thomson-La Ley), p. 323-337.

DOBSON, Andrew (1998): Justice and the environment: conceptions of environmental sustainability and theories of distributive justice (New York, Oxford University Press), $349 \mathrm{pp}$.

GeLLI, María Angélica (2001): Constitución de la Nación Argentina. Comentada y concordada (Buenos Aires, La Ley), 664 pp.

Gerosa Lewis, Ricardo T. (2010): "El proyecto de ley de protección de los glaciares y del ambiente periglacial" en: La Ley Patagonia (Buenos Aires, Thomson-La Ley), pp. 403-410.

GIL Domínguez, Andrés (2010): "Ley de glaciares, futuridad y medida cautelar" en: La Ley (Buenos Aires, Thomson-La Ley), T²010-F, pp. 236.

GonzÁlez Rodríguez, Lorena y Zonis, Federico (2012): "Plena vigencia del Régimen de Presupuestos Mínimos para la Preservación de los Glaciares y del Ambiente Periglacial" en: La Ley (Buenos Aires, Thomson-La Ley), T² 2012-D, pp. 545-552.

Kelsen, Hans (1995): ¿Quién debe ser el defensor de la Constitución? (Madrid, Tecnos), $82 \mathrm{pp}$.

MARTIN, Liber (2008): "Desarrollo sustentable y ley 7.722 de la Provincia de Mendoza sobre prohibición de utilización desustancias químicas en los procesos minero-metalíferos" en: La Ley Gran Cuyo (Buenos Aires, Thomson-La Ley), pp. 606-612.

MARTínez, Víctor H. (2010): Los conflictos mineros y el derecho positivo argentino (Buenos Aires, Academia Nacional de Ciencias Morales y Políticas), 38 pp.

PINTO, Mauricio (1999): "La prevención del impacto ambiental y la actividad minera" en: La Ley Gran Cuyo (Buenos Aires, Thomson-La Ley), p. 1.

(2008): "Comentario a las recientes normas ambientales mendocinas" en: Revista de Derecho Ambiental (Buenos Aires, LexisNexis) No 13 enero/marzo, pp. 171-185.

(2012a): "Tribulaciones jurídicas sobre el conflicto minero-ambiental en Mendoza" en: La Ley Gran Cuyo (Buenos Aires, Thomson-La Ley), p. 239.

(2012b): "Las competencias ambientales a diez años de la Ley 25.675" en: Revista de Derecho Ambiental (Buenos Aires, AbeledoPerrot), No 31 julio-septiembre, pp. 31-384. 
(2013): "Técnicas y principios aplicables a las sanciones ambientales" en: Jurisprudencia Argentina (Buenos Aires, AbeledoPerrot), T²013-IV, suplemento fascículo $N^{\circ}$ 9, pp. 3-20.

Rodriguez Salas, Aldo (2011): "Ley de glaciares, la encrucijada climática" en: La Ley Online (Buenos Aires, Thomson-La Ley). Disponible en: www.laleyonline.com.ar [Accedido el 15 de enero de 2012].

Rodríguez, Carlos Aníbal (2011): "La ley de presupuestos mínimos de protección de los glaciares y del ambiente periglacial (ley 26.639)" en: La Ley. Suplemento Actualidad (Buenos Aires, Thomson-La Ley), p. 1.

Ugarte, Andrés G. (2011): "Comentario a medida cautelar. Suspensión de la Ley de Presupuestos Mínimos de Glaciares y Área Periglacial en la Provincia de San Juan" en: Revista del Foro de Cuyo (Mendoza, Dike), T 111, pp. 171-177.

Valls, Mario F. (1981): Código de Minería de la República Argentina. Concordado y Anotado (Buenos Aires, AbeledoPerrot), 380 pp.

Villalonga, Juan Carlos et al. (2011): "La nueva ley de protección de los glaciares y el ambiente periglacial. Análisis de su elaboración y desafíos actuales" en: DI PAOLA, María Eugenia [ed.], Informe Ambiental Anual 2011 (Buenos Aires, Fundación Ambiente y Recursos Naturales), pp. 272-276.

Wagner, Lucrecia S. (2011): Problemas Ambientales y Conflicto Social en Argentina: Movimientos socioambientales en Mendoza. La defensa del agua y el rechazo a la megaminería en los inicios del Siglo XXI [tesis doctoral] (Buenos Aires, Universidad Nacional de Quilmes), 486 pp.

\section{Documentación citada}

Noticias del SenAdo (2014): Respaldan solicitud para la protección de los glaciares en Chile. Disponible en: http://www.senado.cl/respaldan-solicitud-para-la-proteccion-de-los-glaciares-en-chile/prontus_senado/2014-04-23/111746.html

\section{Jurisprudencia citada}

Roca, Magdalena con Buenos Aires, Provincia de (1995): Corte Suprema de la Nación Argentina. Sobre acción de inconstitucionalidad. 16 de mayo de 1995 (Fallos 318:992).

Villivar con Provincia del Chubut y otros (2007): Corte Suprema de Justicia de la Nación Argentina. 17 de abril de 2007.

Mendoza, Provincia de con Estado Nacional (2009): Corte Suprema de la Nación Argentina. Acción de inconstitucionalidad. 26 de marzo de 2009.

A.O.M.A. y otras con Estado Nacional (2010): Juzgado Federal de 1a Instancia Nro. 1 de San Juan. 2 de noviembre de 2010.

Minera Argentina Gold S.A. con Estado Nacional (2012): Corte Suprema de la Nación Argentina. Acción de inconstitucionalidad. 7 de marzo de 2012.

Barrick Exploraciones Argentinas S.A. y otro con Estado Nacional (2012): Corte Suprema de la Nación Argentina. Acción de inconstitucionalidad. 7 de marzo de 2012.

\section{Normas citadas}

\section{a) Normas de ámbito nacional}

Constitución de la Nación Argentina. Boletín Oficial, 23 agosto 1994.

Ley $N^{\circ} 22.351$, Parques nacionales, monumentos naturales y reservas nacionales. Boletín Oficial, 12 diciembre 1980.

Ley $N^{\circ}$ 24.051, Residuos peligrosos. Boletín Oficial, 17 enero 1992.

Ley No 25.675, Política Ambiental Nacional. Boletín Oficial, 28 noviembre 2002. 
Ley N²5.688, sobre Gestión de Aguas. Boletín Oficial, 3 marzo 2003.

Ley $\mathrm{N}^{\circ} 26.418$, de Protección de glaciares y ambiente periglacial, sancionada por el Congreso Nacional el 22 de octubre de 2008, vetada por el Poder Ejecutivo por Decreto 1837/08 publicado el 10 noviembre 2008.

Ley $N^{\circ}$ 26.639, Régimen de Presupuestos Mínimos para la Preservación de los Glaciares y del Ambiente Periglacial. Boletín Oficial, 28 octubre 2010.

Decreto $N^{\circ}$ 1837, Poder Ejecutivo Nacional. Obsérvase Proyecto de Ley 26.418. Boletín Oficial, 11 noviembre 2008.

Decreto $N^{\circ}$ 207, del Poder Ejecutivo Nacional. Apruébese la reglamentación de presupuestos mínimos para la preservación de los glaciares y del ambiente periglaciar. Boletín Oficial, 1 marzo 2011.

b) Normas de ámbito provincial

Ley Provincial de La Rioja $N^{\circ}$ 8.137, que prohíbe la explotación minera a cielo abierto con técnicas correspondientes al proceso de lixiviación con cianuro, mercurio y/o cualquier otra sustancia contaminante. Boletín Oficial, 20 marzo 2007.

Ley Provincial de San Luis $N^{\circ}$ 634, prohíbe el uso del cianuro en minería. Boletín Oficial, 1 octubre 2008.

Ley Provincial de Chubut $N^{\circ} 5.001$, prohíbe la actividad minera metalífera en la modalidad a cielo abierto y la utilización de cianuro en los procesos de producción minera. Boletín Oficial, 8 mayo 2003.

Ley Provincial de Tucumán $N^{\circ} 7.879$, prohíbase la actividad minera metalífera en la modalidad a cielo abierto y la utilización de cianuro y mercurio en los procesos de producción minera. Boletín Oficial, 20 abril 2007.

Ley Provincial de La Pampa No2.349, prohíben en el territorio de la Provincia de La Pampa la utilización de toda sustancia química contaminante en el proceso de cateo, prospección, extracción, explotación, tratamiento y/o industrialización de minerales metalíferos. Boletín Oficial, 14 septiembre 2007.

Ley Provincial de Córdoba $N^{\circ}$ 9.526, prohíbase la actividad minera metalífera en la modalidad a cielo abierto y la utilización de cianuro y mercurio en los procesos de producción minera. Boletín Oficial, 24 septiembre 2008.

Ley Provincial de Tierra del Fuego $N^{\circ} 853$, prohíbase la actividad minera metalífera en la modalidad a cielo abierto y la utilización de cianuro y mercurio en los procesos de producción minera. Boletín Oficial, 21 septiembre 2011.

Ley Provincial de Mendoza № 7.722, prohíbe en el territorio de la Provincia de Mendoza, el uso de sustancias químicas como cianuro, mercurio, ácido sulfúrico, y otras sustancias tóxicas similares en los procesos mineros metalíferos. Boletín Oficial, 20 junio 2007.

Ley Provincial de Salta N ${ }^{\circ} 7.625$, Ley sobre inventario y protección de glaciares. Boletín Oficial, 5 agosto 2010.

Ley Provincial de La Rioja, № 8.773, sobre protección de los glaciares. Boletín Oficial, 8 julio 2010.

Ley Provincial San Juan N 8.144, sobre protección de los glaciares. Boletín Oficial, 14 julio 2010.

Ley Provincial Jujuy $N^{\circ}$ 5.647, sobre protección de los glaciares. Boletín Oficial, 8 julio 2010.

Ley Provincial San Juan N 4.392, Código de Aguas de San Juan. Boletín Oficial, 12 abril 1978.

Ley Provincial Río Negro $N^{\circ} 3.981$, que prohíbe el uso del cianuro y/o mercurio en el proceso de extracción, explotación y/o industrialización de minerales metalíferos. Boletín Oficial, 11 agosto 2005. 